\title{
Group polarization effects on decisions by selected Kenyan secondary school disciplinary panels
}

Peter J. O. Aloka and Olaniyi Bojuwoye

\begin{abstract}
:
This study investigated social group phenomenon of group polarization effects on disciplinary hearing decisions in selected Kenyan secondary school. The participants were 78 school personnel (females $=42 \%$ and males $58 \%$ ) from ten secondary schools with both unisex ( $\mathrm{n}=39)$ and co-educational schools $(\mathrm{n}=39)$. Both quantitative and qualitative data were collected and analyzed. The results suggested group polarization effects in disciplinary hearing decisions, in that there were shifts from pre to post-disciplinary hearing decisions. Persuasive arguments and social comparisons significantly influenced group polarization decisions.
\end{abstract}

School students' in-disciplined behaviours are precursors to later school dropout and other negative social outcomes (Yahaya, Ramli, Hashim, Ibrahim, Rahman, \& Yahaya, 2009). Student in-disciplined behaviours negatively impact teaching and learning as indisciplined students tend to perform poorly in school (Andrews \& Taylor, 1998). Joubert, de Waal, and Rossouw (2004) also contend that ill-disciplined students make school environment unsafe and less secure for other students.

Students' misconducts also have very profound effects on teachers. Yahaya et al (2009) assert that student in-disciplined behaviours make teachers to experience fear for their safety and make them lack sense of dignity at work, feel angry, humiliated and depressed. According to Slavin (2003), misbehaving students undermine the confidence and sense of personal safety of teachers. Kenyan school authorities have, however, been responding to their students' violent behaviours. Perhaps piqued by the negative consequences of student in-disciplined behaviours Kenyan school authorities are reported to have adopted a number of measures and practices in order to promote healthy behaviours in their students (Aloka, 2012). Corporal punishment employed as an earlier response to student in-disciplined behaviours had to be banned because of its being largely characterized by negative, punitive and reactive measures including human rights abuses.

\section{The Kenyan School Management Context}

Student in-disciplined behaviours in Kenyan secondary schools have been on the increase for some time now and have been of great concern to school authorities, parents and Kenyan government (Kindiki, 2009). These student in-disciplined behaviours are of various types including bullying, homicide, vandalism, arson, drug and alcohol abuses, 
cheating in examinations, stealing of personal and school properties, not completing homework assignments and truancy (Kindiki, 2009). Violent behaviours by Kenyan secondary school students first got international attention, in May 1997, when fifty-seven (57) students of Bombolulu Girls Secondary School, Mombasa, perished in hostel fire allegedly started by other students. In 1999 four student leaders (prefects) of another Kenyan secondary school were burnt to death by other students who set the school hostel on fire in an apparent attempt to prevent the prefects from reporting to the school authorities punishable offences by fellow students (Kindiki, 2009). Both 2002 and 2005 also witnessed cases of arson in different Kenyan secondary schools by students (Aloka, 2012). More recently, in July 2012, over 300 students of two Kenyan secondary schools were reported to have boycotted classes and violently protested their school authorities' decision refusing to shift entertainment sessions from daytime to nighttime (Wanjohi, 2012).

School guidance and counselling programme was then introduced as strategy for intervening in student in-disciplined behaviours and for assisting in career decisionmaking, planning and enhancing students' academic performance. Further measure for responding to student in-disciplined behaviours was the establishment, in 2009, of the Kenya Secondary School Student Council (KSSSC). Jeruto and Kiprop (2011) report that KSSSC functions to ensure more participatory secondary school governance including taking students' interests into consideration by making them part and parcel of decisionmaking in the administration of schools. Secondary school authorities also periodically organize school Baraza (Kiswahili word for public gathering) where all teachers and students meet and talk freely or express concerns about problems affecting them in the schools and how to prevent in-disciplined behaviours from occurring (Aloka, 2012). Some civil society and non-governmental organizations in Kenya have also strengthened schools' efforts at responding appropriately to student ill-disciplined behaviours by providing various forms of support to schools. For instance, the National Council of Antidrug Agency, (NACADA) regularly visits schools to offers drug education and counselling to students (Aloka, 2012).

A school disciplinary panel ensures that students adhere to the expected norms of conduct including orderly school and classroom behaviours (Bridge House, 2012). Yahaya, et al (2009) assert that a school disciplinary panel manages student behaviours in school by developing procedures for monitoring students' behaviours and dealing with breaches of disciplinary policies and occurrences of unacceptable behaviours.

Group polarization. Perhaps, the most important rationale for employing small group of people to make decisions is the existence of the phenomenon of group polarization, a tendency of making discussion in the group to intensify convergence of group members' opinions (Klein \& Olbrecht, 2011). Isenberg (1986) and Zhu (2009) describe group polarization as the tendency for group members' pre-meeting average position to be amplified in their post-meeting collective decision. Group polarization is the result of shifts from individually made pre-group meeting decisions to post- group meeting collective decisions concerning a group task (Meyer, 1989; Kim \& Park, 2010). According to Friedkin and Johnsen (2011), members of social groups are expected to hold individual pre-group meeting opinions or decisions concerning group tasks before such tasks are 
discussed in group meetings. However, during such group meeting the tendency is for members to select or to settle for one option from a set of alternatives presented to the group and collectively consider that option to be the choice of the group (Friedkin \& Johnsen, 2011). The effects need investigation in the context of school discipline practices.

The dynamic interactions in the group process is said to be responsible for group polarization. This is because, as members discuss a group task and as new or additional information, ideas or opinions are provided, better perspectives on group task are gained as well as new or better understanding, insight or new awareness and comprehension of the group task and by so doing group members are persuaded to shift from their pregroup meeting individually made decisions to post group meeting collective decisions (Browman, 2005; Conkie, 2007). New or additional information becomes even more persuasive when provided by group members who are considered to be experts in or eyewitnesses to the subject matter being discussed in the group and who are perceived as more likely to be providing true, credible or authentic information and, therefore, persuasive (Conkle, 2007). Not only are members of a small social group influenced by persuasive arguments, as just described, they are also influenced by social comparison the tendency for each individual member of a group to feel a need for solidarity with other members rather than be odd one out and, therefore, elect to align with or support other members (Keyton, 2000). According to social comparison theory each individual member of a small social group is constantly motivated for approval by others (Grodzki, 2011) as each member perceives and presents him/herself in socially acceptable or desirable manner to other members of the group (Isenberg, 1986). Boyer (2012) also states that each individual member of a social group tries to compare him/herself with other members of the group and, therefore, readjust his/her initial individual response or position in the direction of the dominant positions of the other group members.

Quality of arguments. Persuasive argument and social comparison are not the only factors providing insight into the limitations of individually made decisions, other factors of in small group decisions, making them more superior to individual decisions are associated with the personality characteristics of group members. Different personalities are suited to different tasks and aspects of group life and these differences operate within groups to influence the dynamic interactions among the members leading to group collective decisions (Levin \& Moreland, 1998; Patalano \& LeChair, 2011). According to Greenwald (2002), the decision a person makes in a group may not necessarily be because of the validity or truthfulness of information provided in the group but may be because of the personality characteristics of the recipient or the provider of the information. Such characteristics may include strong personality, strong ego and selfopinionated individual depending on the position of the recipient or the provider of the information within the hierarchy of the organization.

Both social comparison and persuasive arguments, explain the dynamic interactions within disciplinary panels leading to group polarization. The Social Comparison theory explains the shifts from pre to post disciplinary hearing decisions that occur among members after comparing their opinions with others which can be upward, lateral or downward depending on the panel member to whom the reference in comparison is being made. This means that an individual's decision in the panel is not static but can be 
changed during the disciplinary hearing meetings. The Persuasive Arguments theory explains the nature of dynamic interactions within the disciplinary panels that make the members to shift their decisions, due to the pool of arguments that are available to them. These arguments may be in terms of new information about the problem, the credibility of the information, the persuasiveness of the new information and the trustworthiness or credibility of the person presenting the arguments about the issue being discussed by the group.

Influence of demographics. Personality characteristics or behaviour tendencies which influence group decisions may also be gender, age and experience. For instance, women's decision-making behaviours are said to be different from men as women are said to be more affected by the environment of their groups and tend to seek for more information as well as dedicate more time to decision-making process than men (Hatala \& Case, 2000; Venkatesh, Morris, \& Ackerman, 2000). Men are reported to be more dominant, assertive, objective and realistic when handling group tasks and these make them behave different from women when it comes to making decisions (Lazarraga et al, 2007). Age is another personality factor, in decision making in a group, which determines whether the individual will influence or be influenced to take a particular position during group discussion. According to Conkle (2007) older people have a lifetime of experience to draw from and can bring their deliberative capacities to bear when it matters. However, Watanabe and Shibutani (2010) are of the view that decision making processes among older people tend to be characterized by lack of flexibility in learning and changing of decisions as compared with younger people as older people tend to have strong personality, strong ego or are self-opinionated. Masuda, Sakagami, and Hirota (1997) state that older people do not change easily from their old ways while, on the other hand, younger people, being very dynamic, are often more willing to change their opinions easily.

\section{Goals of the Study}

The study investigated evidence of the existence of group polarization in disciplinary hearing decisions by selected Kenyan secondary school disciplinary panels, as well as factors which might have been responsible for group polarization in the disciplinary hearing decisions. The research study also was guided by the following question: What factors influence decisions to post-disciplinary hearing group decisions in the Kenyan school setting?

\section{Method}

\section{Participants and Setting}

The study setting was the Rongo district of Kenya. A total of 78 disciplinary panel members, from the selected ten secondary schools, participated in the study and these are made up of 45 males and 33 females, with 39 drawn from five coeducational schools, 23 from three Boys' Only schools and 16 from two Girls' Only schools (see Table 2).

\section{Research Instruments}

Data were collected using a demographic Questionnaire and the Modified Choice Dilemma Questionnaire (Ronay \& Kim, 2006), and to enable estimations of the changes from pre to post disciplinary hearing decisions. 
The MDCQ is a measure of decisions by individuals before and after group deliberations or meetings (Appelt, Milch, Handgraaf \& Weber, 2011). The questionnaire has response options for rating decisions by requesting respondents to choose between the odds of decisions (Freedman, 2007). The questionnaire presented four different dimensions of presenting student behaviours on which respondents were to rate their decisions. There are the nature or types of presenting student disciplinary behaviours (acceptable or unacceptable as indicated by the school rules and regulations), the characteristic tendencies of the misbehaving students (first or regular offenders even with repeated warning or offenders with extenuating circumstances), the effects of the disciplinary behaviours on the relationships between the misbehaving students and others (whether or not the behaviours have led to serious harm, abuses or violation of other students' rights) and the effects of presenting student disciplinary behaviours on the disciplinary tones of the schools (whether or not the behaviour has potential to embarrass the school or place it in rather bad light) (Aloka, 2012).

The respondents completed the MDCQ twice, before and after the disciplinary hearing meetings, to indicate their decisions on the four dimensions of the presenting student disciplinary behaviours before the disciplinary hearing meetings and their decisions after the meetings. The estimated differences, in quantitative terms, between the pre and post disciplinary hearing decisions were then calculated. The validity of the instruments was ascertained by making clear statements regarding decisions on presenting student disciplinary behaviours and the four dimensions of the disciplinary behaviours on which decisions were to be made. Further confirmation of validity was done by a panel of judges who are psychologists and experts in group procedures. The split-half internal reliability co-efficient estimate for the ModifiedMCDQ in the present study was 0.608.

\section{Interviews}

In-depth individual one-on-one semi-structured interviews were employed for gathering qualitative data. Twenty participants were interviewed on their experiences of disciplinary hearing processes, particularly regarding the factors in the dynamic interactions among disciplinary panel members, during disciplinary hearings, which they considered might have influenced their decisions on presenting student disciplinary behaviours. The semistructured interviews allowed researchers to follow up ideas, to probe responses and investigate motives and feelings of participants (Bell, 2005; Eliahoo, 2011). Interview process also allows researchers to observe and ask questions thus providing opportunity to look at issues as if through the eyes of the participants (Bojuwoye \& Akpan, 2009).The interviews were recorded and transcribed for data analysis.

\section{Procedure}

Ethical clearance for the study was first obtained from the University of the Western Cape Senate Research Ethics Committee. Permission to conduct the study in the selected Kenyan secondary schools was also obtained from the Ministry of Education, Kenya, and from the selected school authorities. Introductory visits were made to the selected secondary schools to inform prospective participants of the purpose of the study and the conditions for participation. This information was provided to groups of potential participants both orally and in writing. Other ethical principles by which the study 
process was framed include assurance of the confidentiality and anonymity of participants' responses, voluntary participation, informed consent, consent to electronic recording of the interviews and permission to withdraw at any stage of the study.

Two participants were interviewed in each of the ten schools involved in the study. Each interview session lasted between 30 to 45 minutes. During the interviews participants were given an opportunity to ask researchers questions. The participants were debriefed after the interview sessions.

\section{Data Analysis}

The Paired Samples T-tests were used to test for, significant differences between the pre and post disciplinary hearing response scores with group polarization. This was to ascertain whether or not group polarization was evident in the disciplinary panels' decisions. Further analyses of the participants' response scores on the MCDQ were done on the basis of subgroups of the participants, that is, by gender, age, teaching experiences and school affiliation to ascertain the effects of these variables on the group polarization in the disciplinary hearing decisions.

The qualitative were thematically analyzed with multiple readings of the interview transcriptions and the review of data in order to gain understanding and for appropriate interpretation of participants' responses. This was followed by identification of patterns in the participants' responses, which in turn led to themes related to the factors participants considered to have influenced polarization in the disciplinary panels' decisions.

\section{Results}

Table 1 presents the descriptive statistics of the pre and post disciplinary hearing response scores on the MCDQ and the estimated differences between the pre and post disciplinary hearing meetings' mean response scores. The table also display information about the results of the Paired Samples T-tests performed on the participants' response scores on the MCDQ

\section{Response Shifts in Panel Decision Making}

According to the information displayed in Table 1, the results of the Paired Samples T-test performed on the participants' response scores on the MCDQ revealed that the difference between the pre and post response scores is statistically significant $(t=6.892, p=0.000)$. The evidence suggests that disciplinary panels of selected Kenyan secondary schools make significant decision changes from their pre to post hearings; likely from group polarization. 


\begin{tabular}{lc}
\hline Pre-disciplinary hearing mean response score & 5.30 \\
Post-disciplinary hearing response score & 3.05 \\
Paired Differences & \\
$\quad$ Estimated difference between pre and post response scores & 2.26 \\
S.D. & 1.78 \\
Std. Error Mean & 0.20 \\
95\% Confidence interval of the Difference & .99 \\
$\quad$ Lower & 1.79 \\
$\quad$ Upper & 6.90 \\
t $\quad 77$ \\
Sig (2 tailed) & $0.000^{\star \star \star}$ \\
\hline
\end{tabular}

Influence of demographics. Table 2 provides evidence to suggest that female members recorded more differences $($ Mean $=2.62 ; \mathrm{SD}=0.91$ ) made decision changes more than did their male peers (Mean $=0.80 ; \mathrm{SD}=0.91$ ). Younger panel members (aged 20 to 39 years) recorded more differences (Mean $=3.97 ; \mathrm{SD}=1.42$ ) than older panel members (aged 40 to 59 years) (Mean $=1.145$; $\mathrm{SD}=1.41$ ). Panel members with less teaching experience (ranging from 1 to 20 years) recorded more differences (Mean $=4.27$; $\mathrm{SD}=0.94$ ) than panel members with more teaching experience (more than 21 years) (Mean $=1.44 ; \mathrm{SD}=1.89$ ). Panel members affiliated to Girls' only schools recorded more differences (Mean $=2.24 ; \mathrm{SD}=0.56)$ than members affiliated to the other categories of Co-educational schools (Mean $=1.35, \mathrm{SD}=0.89$ ) and Boys' Only schools (Mean $=1.47$; $\mathrm{SD}=0.77)$. The results therefore indicate that male members of the disciplinary panels made little changes from their pre to post disciplinary hearing decisions as compared with their female counterparts; older members of the disciplinary panels made the least changes from their pre to post disciplinary hearing decisions as compared with younger teacher panel members; highly experienced members with more than 26 years teaching experiences made relatively little changes from their pre to post disciplinary hearing decisions as compared with their less experienced counterparts and panel members from Girls' Only schools made more changes from their pre to post disciplinary hearing decisions that the members of the other two school categories (see also Table 3).

The results of the regression analysis revealed that ages and years of teaching experiences of panel members significantly predicted the shifts or changes from pre to post disciplinary hearing response scores $(\beta=-0.414, p<0.05, \beta=-0.300, p<0.05)$ respectively. School category was not found to be significant predictor $(\beta=-0.12, p>$ 0.05) in the shifts or changes from pre to post disciplinary hearing decisions (see Table 4). 


\begin{tabular}{|c|c|c|c|c|c|}
\hline Variables & $\mathrm{N}$ & Pre-disciplinary & Post-disciplinary & Estimated differences & SD \\
\hline \multicolumn{6}{|l|}{ Gender } \\
\hline Male & 45 & 4.93 & 4.75 & 0.80 & 0.91 \\
\hline Female & 33 & 5.87 & 3.61 & 2.62 & 0.91 \\
\hline \multicolumn{6}{|l|}{ Age groups } \\
\hline $20-29$ years & 21 & 7.45 & 2.95 & 4.50 & 1.95 \\
\hline $30-39$ years & 28 & 6.46 & 3.02 & 3.44 & 0.89 \\
\hline $40-49$ years & 14 & 3.87 & 4.05 & 0.82 & 1.73 \\
\hline $50-59$ years & 15 & 2.07 & 3.54 & 1.47 & 1.08 \\
\hline \multicolumn{6}{|l|}{ Years of teaching experience } \\
\hline $1-5$ years & 33 & 7.24 & 2.29 & 4.95 & 1.62 \\
\hline $6-10$ years & 14 & 7.10 & 3.55 & 3.55 & 0.22 \\
\hline $11-15$ years & 5 & 5.36 & 4.88 & 4.80 & 1.47 \\
\hline $16-20$ years & 6 & & 0.33 & & \\
\hline $21-25$ years & 8 & 2.81 & 4.36 & 1.55 & 1.78 \\
\hline $26-30$ years & 12 & 2.00 & 3.34 & 1.34 & 1.99 \\
\hline \multicolumn{6}{|c|}{ School affiliations of panel members } \\
\hline Boys only schools & 23 & 4.86 & 6.33 & 1.47 & 0.21 \\
\hline Girls only schools & 16 & 4.13 & 6.37 & 2.24 & 0.56 \\
\hline Co-educational schools & 39 & 6.07 & 4.72 & 1.35 & 0.33 \\
\hline
\end{tabular}

Table 3

Summary Results of Independent Samples t-Test Performed on the Pre and Post Disciplinary Hearing Response Scores by Male and Female Respondents

\begin{tabular}{|c|c|c|c|c|c|c|c|c|c|}
\hline & \multicolumn{2}{|c|}{$\begin{array}{l}\text { Leven's Test for } \\
\text { equality of variances }\end{array}$} & \multicolumn{3}{|c|}{ t-test for equality of means } & \multirow[b]{2}{*}{$\begin{array}{c}\text { Mean } \\
\text { diff. }\end{array}$} & \multirow[b]{2}{*}{$\begin{array}{l}\text { Std. Err } \\
\text { diff. }\end{array}$} & \multicolumn{2}{|c|}{$\begin{array}{l}95 \% \text { confidence } \\
\text { interval of difference }\end{array}$} \\
\hline & $\mathrm{F}$ & Sig. & $\mathrm{t}$ & df & $\begin{array}{l}\text { Sig. } \\
\text { (2 tailed) }\end{array}$ & & & Lower & Upper \\
\hline $\begin{array}{l}\text { Equal } \\
\text { variances } \\
\text { assumed }\end{array}$ & 0.705 & 0.404 & -7.741 & 76 & $0.000^{*}$ & -1.8163 & 0.2431 & -2.300 & -1.332 \\
\hline $\begin{array}{l}\text { Equal } \\
\text { variances } \\
\text { not assumed }\end{array}$ & & & -7.290 & 62.36 & 0.000 & -1.8163 & 0.2491 & -2.314 & -1.318 \\
\hline
\end{tabular}

Note. ${ }^{*} \mathrm{p}<0.05$

Table 4

Summary Results of Regression Analysis Performed on the Shifts from Pre to Post Disciplinary Hearing Decisions by Members of the selected Kenyan Secondary School Disciplinary Panels, on the Bases of Gender, Age, Experiences and School Affiliation

\begin{tabular}{|c|c|c|c|c|c|}
\hline \multirow[b]{2}{*}{ Model } & \multicolumn{2}{|c|}{ Un-standardized coefficients } & \multicolumn{2}{|c|}{ Standardized coefficients } & \multirow[b]{2}{*}{ Sig. } \\
\hline & B & Std. Error & Beta & $\mathrm{t}$ & \\
\hline constant & 4.562 & 0.186 & & 24.539 & 0.003 \\
\hline Age of panel members & -0.537 & 0.087 & -0.414 & -6.913 & 0.000 \\
\hline Years of teaching experiences & -0.216 & 0.047 & -0.300 & -4.590 & 0.000 \\
\hline School category & -0.10 & 0.006 & -0.12 & -1.64 & 0.100 \\
\hline
\end{tabular}

Influences of group response shifts. In terms of persuasive arguments participants reported that they experienced sharing of new or additional information among themselves as members of the disciplinary panels during disciplinary hearing processes. Table 5 and 6 present information related to excerpts from the interview transcripts related to how participants described the factors which influenced the changes from their pre to post disciplinary hearing decisions $<$ insert Table 5 and $6>$.

The new or additional information was not available to them before the disciplinary hearing meetings and that this new or additional information enabled members to see, appreciate or consider all dimensions of or associated factors related to the presenting 
student disciplinary behaviours leading members to new or better understanding, insight and comprehension to the presenting student behaviours. With the new or additional information they were also see alternatives solutions to the problems created by the presenting student disciplinary behaviours. Participants also reported that when information shared during disciplinary hearing was provided by members perceived to be experts on presenting student behaviours, eye-witnesses to the manifestations of the presenting problem behaviours or victims of the presenting student disciplinary behaviours, these factors further encouraged or persuaded members of the disciplinary panels at the disciplinary hearings to change their pre disciplinary hearing decisions to new decisions agreeable to all members of the panels.

The nature of information shared among members of the disciplinary panels during disciplinary hearings was not the only factor reported as being responsible for changes from their pre to post disciplinary hearing decisions. Participants also reported that they did not only shared new or additional information among themselves but that they were also engaged in comparing themselves with each other as members of the same group. Each member compared his or her opinion with those of other members of the disciplinary panel and depending on the age, teaching experience or position of members of the panel with whom comparison was being made determined the realignment of decisions of members. For instance, participants reported that respect for an older member or member who is more experienced or in higher position in the school's hierarchy could influence realignment of decisions in favour of or along the decisions of the older more experienced and high ranking members of the disciplinary panels.

\section{Discussion}

The aim of this study was to investigate evidence of group polarization in decisions by Kenyan secondary school disciplinary panels and to ascertain factors which could have been responsible for group polarization. The results of the study clearly revealed that group polarization was evident in the disciplinary hearing decisions of the Kenyan secondary school disciplinary panels studied. The finding is consistent with previous study findings by Bowman (2005); Freedman (2007); Krizan \& Baron (2007); Kinga et al. (2010) and Keck et al. (2011) which revealed that when small groups of people meet to deliberate on group tasks there is tendency for convergence of opinions or positions regarding the tasks by the end of deliberations on the tasks by the members of the teams or committees. 
Table 5

Participants Statements on Persuasive Arguments as Factors Influencing Changes in Their Decisions During Disciplinary Hearings

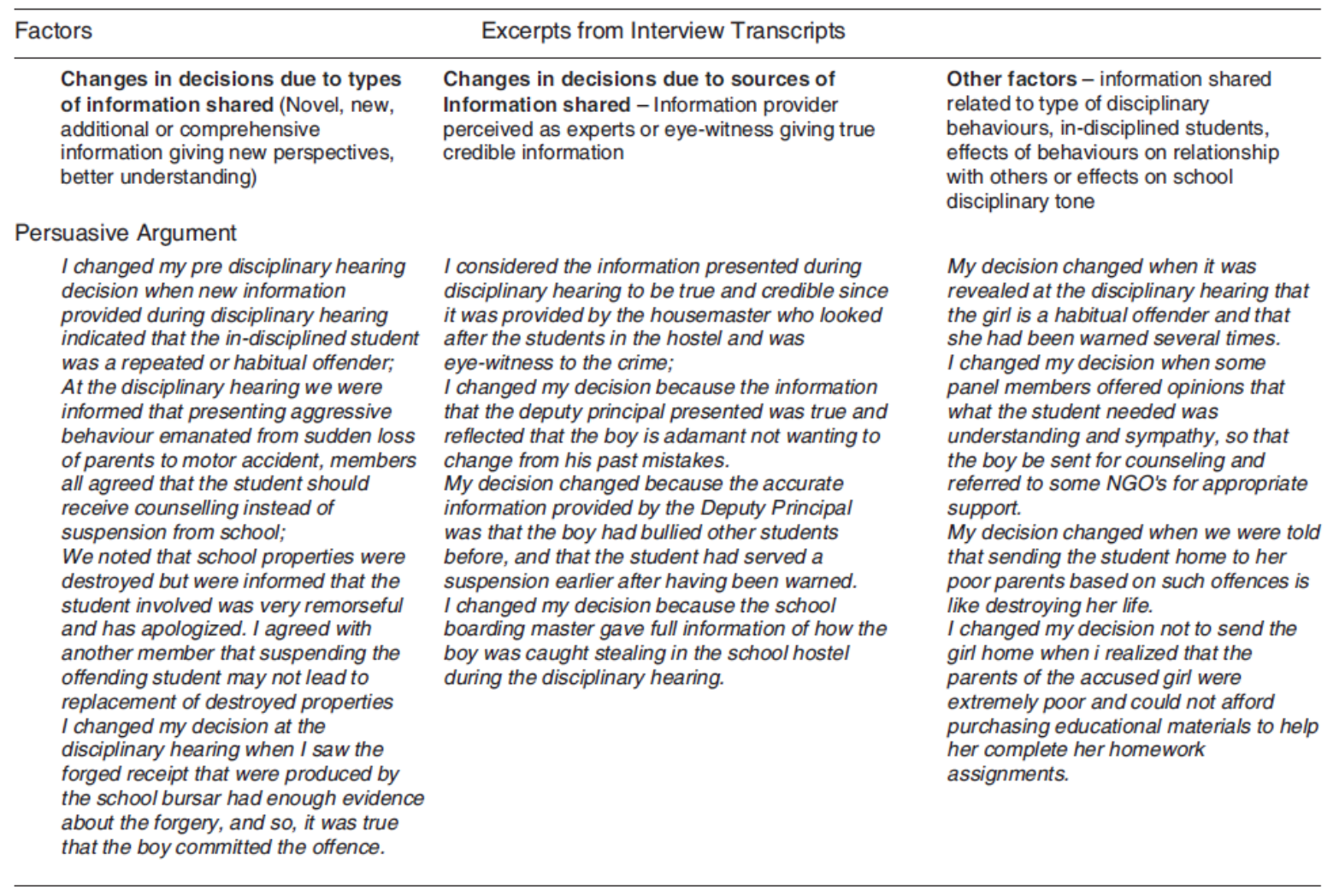

A number of factors are responsible for the small group phenomenon of group polarization. Meyers (1989) asserts that group discussions always tend to influence group members to shift their opinions from the ones they held before the group discussion. During group discussions members freely share or exchange information, opinions or ideas about what is being discussed and that such information may not be available to them before the group meeting (El-Shinnawy \& Vinze, 1998; Zhu, 2009). Therefore, one factor which that tends to influence members such that by the end of the group discussions the opinions of members change, becoming closer or there is a tendency of a group consensus, is the information shared during group meeting. As Sunstein (1999) found that the decision making among people dealing with a common group task always conform to some average opinion after the group deliberations.

This study revealed that female, younger and less experienced members of the disciplinary panels studied were easily influenced to change their decisions, researchers caution in how these results are interpreted. Maccoby (1998) notes that females' decision making behaviours may be motivated by more of conflict-avoidance reactions and not necessarily weakness. Women's behaviours in group often tend towards fostering cooperation, compromise and maintenance of peaceful atmosphere. Although older and more experienced members appeared reluctant to shift their positions in group discussions, however, Rana, Murtaza, Noor, and Rehman (2011) and Rolison, Hanoch, and Wood (2012) are of the opinions that older adults make cautious decisions as compared to younger people who make risky decisions and that cautious decisions are often found to be more reformative and more likely to promote behaviour development rather than destructive as it is characteristic of risky decisions. 
Group members' decision making behaviours are influenced by their concern about their status in the group making them to constantly perceive and present themselves in socially desirable manner to other members of the group (Schmalisch, Bratiotis, \& Muroff, 2010). Group members invest time, observe and listen to other members' opinions to determine what is correct and to learn to present to other members what is correct and to present self in a socially acceptable way (Brown, 1999). Suls and Wheeler (2000) also assert that when one is in a group he/she wants to know where other members stand especially on the choices that involve a group conclusion. Individual member of a group continuously process information about how other members of the group present themselves and as all members engage in the same comparing process the results are average shift in the direction of greater perceived value of the final decision being made (Aronson, Wilson, \& Akert, 2002).

Disciplinary decisions may be made because of members' desire for solidarity among themselves (Crocker \& Park, 2002; Jarvis 2000). Thus, aspects of group life and operate to influence the dynamics leading to group decisions (Levin \& Moreland, 1998; Patalano \& LeChair, 2011).

\begin{tabular}{l} 
Table 6 \\
Participants' Statements on Social Comp \\
Hearings \\
\hline Factors \\
\hline Participants changed their \\
decisions and aligned with others \\
because opinion givers were older, \\
more experienced or occupied \\
higher positions in the school \\
hierarchy \\
Social Comparisons \\
I aligned my decision with the \\
chairperson of our panel, the school's \\
deputy principal, who insisted that \\
growing cases of bullying should not \\
be tolerated and that a strong warning \\
be sent to students by suspending \\
offenders. \\
My decision changed because older \\
panel more experienced members felt \\
that the offending were insistent that \\
offending student cannot be sent away \\
from school during examination; \\
I changed and agreed with the deputy \\
principal of the school that student \\
violent behaviours should not be \\
tolerated in the school; \\
I agreed with the chairperson of the \\
panel and other more experienced \\
members that when in-disciplined \\
behaviour of a student seriously violate \\
another student's rights and causing \\
harm to the latter the offending student \\
must be sanctioned.
\end{tabular}

Aligning with others because previous decisions were rather harsh and unlikely to achieve desired outcome or and aligning with others for the purpose of solidarity with others and to avoid being alone

I changed my decision to align with other panel members who felt that offence committed was not deliberate and that the offending student showed remorse;

My decision changed and I agreed with other panel members that past records showed the student to be generally well behaved. My opinion about the presenting behaviour changed when I realized that only two of us held contrary opinions from others concerning the nature of the in-disciplined behaviour; I changed my decision and agreed to go along with the position I saw other members of the panel are aligning with.

\author{
I changed my decision to align with \\ others who agreed that suspending \\ offending student may lead to her \\ dropping out of school which may also \\ disrupt her educational development. \\ I aligned my decision with other \\ members of the panel that an offending \\ student should not be suspended during \\ examination period and particularly \\ when the student is yet to be found \\ guilty; \\ I agreed with another member that \\ suspending or expelling an offending \\ student from school will not reform him \\ but destroy him; \\ I agreed with another member that \\ involving parents in student discipline \\ by writing strongly worded letter to \\ parents to take actions might be a \\ better option to sending students away \\ from school;
}

\section{Implications of the Study}

The complexity of decision making and decisions on the management of such an important aspect of adolescent secondary school student development, as behaviours, mean that no single individual can possess the quantum of knowledge required for such decision. The implication, therefore, is that decisions made by individual school principal 
certainly suffer very serious limitations. This study therefore strengthen the merits to use a small group or committee of teachers, rather than individual school principal, in making decisions for the management of student behaviours in Kenyan secondary schools. Disciplinary panels with teachers with diversity in characteristics ensure good quality decisions.

\section{Limitations of the Study}

Some participants may have been influenced in their self-reporting by social desirability. As process evidence, participants were rather cautious in giving certain information, while others may not have completed or responded to the instrument appropriately. This was brought to the surface when conducting interviews with selected panel members, and some participants appeared to be restrained to disclose certain information concerning their schools. Despite the above study limitations, the findings are reasonably accurate and provide useful baseline information for future research and policy decisions.

\section{Conclusion}

The results of the study confirming evidence of group polarization in disciplinary hearing decisions by Kenyan disciplinary panels could be translated to imply that such decisions are arrived at by consensus, have greater acceptance and are widely supported. It may also mean that Kenyan secondary school disciplinary panel decisions are arrived at as members bring different perspectives to decision making process (due to new, additional and relevant information and different expertise), as alternatives solutions to problems are considered and as information is critically analyzed and integrated.

The study found that the pre disciplinary hearing individually made decisions by members of the disciplinary panels were different from the post disciplinary hearing decisions. The members of the disciplinary panels studied exhibited decision making behaviours leading to convergence of positions or opinions of members of the disciplinary panels regarding their decisions on presenting student disciplinary behaviours at the end of the disciplinary hearings different from their divergent individually made decisions before the disciplinary hearings. 


\section{References}

Abraham, P. B., Hinke A. K., \& Frans, W. S. (2007). Social comparison and satisfaction with one's social life. Journal of Social and Personal Relationships, Volume, 24(2), 197-205.

Albarracina, D., Wallaceb, H. M., Hartc, W., \& Brownd, R. D. (2012). How judgments change following comparison of current and prior information. Basic and Applied Social Psychology, Volume, 34(1), 44-55.

Aloka, P. J. O. (2012). Group polarization in decision making (Unpublished doctoral thesis). University of the Western Cape, Cape Town, South Africa.

Andiliou, A., Ramsay, C. M., Murphy, P. K., \& Fast, J. (2012). Weighing opposing positions: Examining the effects of intra-textual persuasive messages on students' knowledge and beliefs. Contemporary Educational Psychology, Volume, 37, 113127.

Baron, R. S. (2005). So right its wrong: Group think and the ubiquitous nature of polarized group decision making. Advances in Experimental Social Psychology, 37, 219-253.

Bojuwoye, O. (1997). Student counseling services in a Nigerian University. International Journal for the Advancement of Counseling, 19, 41-53.

Bojuwoye, O. (2002). Small group teaching: Teach you very best. In B. Otaala \& M. A. Opali (Eds.), Proceedings of a regional conference for staff from tertiary institutions from SADC Countries held from 1-3 October 2001 at Hotel Safari, Safari Court and Conference Centre, Windhoek, Namibia, (pp. 139-148).

Bojuwoye, O., \& Akpan, O. (2009). Personal, familial and environmental perspectives in children's reactions to parental divorce in South Africa. Journal of Family Studies, 15(3), 260-273.

Bonito, J. (2011).Interaction and influence in small group decision making. New York, NY: Routledge.

Boyer, L. (2012). Managing conflict: What to do and how to do it. Bradenton, FL: Leadership Options.

Freedman, K. (2007).Effects of collaboration on grade retention decision making (Unpublished master's thesis). State University, Tallahasee, Forida.

Friedkin, N. E. (1999). Choice shift and group polarization. American Sociological Review, 64, 856-875.

Grodzki, J. S. (2011). Role identity: At the intersection of organizational socialization and individual sense making of new principals and vice-principals. Canadian Journal of Educational Administration and Policy, Issue 127. Retrieved December 30, 2011 from http://www.umanitoba.ca/publications/cjeap/pdf files/grodzki.pdf

Gunnarsson, M. (2010).Group decision making. Frederick, MD: Verlag.

Kim, D., \& Park, J. (2010). Cultural differences in risk: The group facilitation effect. Society for Judgment and Decision Making, Volume, 5(5), 380-390.

Kindiki, J. N. (2009). Effectiveness of communication on students discipline in secondary schools in Kenya. Educational Research and Review, 4(5), 252-259.

Kinga, R. C., Hartzelb, K. S., Schilhavya, R. M., Melonec, N.P., \& McGuired, T. W. (2010). Social responsibility and stakeholder influence: Does technology matter during stakeholder deliberation with high-impact decisions? Decision Support Systems, 48(4), 536-547. 
Klein, T., \& Olbrecht, M. (2011). Triangulation of qualitative and quantitative methods in panel peer review research. International Journal for Cross-Disciplinary Subjects in Education (IJCDSE), 2(2), 342-348.

Mercier, H., \& Sperber, D. (2011). Why do humans reason? Arguments for an argumentative theory. Behavioural and Brain Sciences, 34, 57-111.

Olbrecht, M., \& Bornmann, L. (2010). Panel peer review of grant applications: what do we know from research in social psychology on judgment and decision-making in groups? Research Evaluation, 19(4), 293-304.

Suls, J. (2000). Opinion comparison: The role of corroborator, expert, and proxy in social influence. In J. Suls \& L. Wheeler (Eds.), Handbook of social comparison: Theory and research. New York, NY: Kluwer Academic /Plenum Press.

Suls, J. M., \& Wheeler, L. (2000). Social comparison processes: Theoretical and empirical perspectives. Washington, DC: Hemisphere.

Trautmann, S. T., \& Vieider, F. M. (2012). Social influences on risk attitudes: Applications in economics. In S. Roeser, R. Hillerbrand, P. Sandlin, \& M. Peterson (Eds.), Handbook of risk theory (pp. 575-600). Heidelberg, Germany: Springer Verlag.

Zhu, H. (2009). Group polarization on corporate boards: Theory and evidence on board decisions about acquisition of premiums, executive compensation, and diversification. Journal of Operations Management, Volume, 27(6), 495-511.

Wanjohi, G. (2012, July 18). 300 Students From Two Schools in Nyandarua Go On Strike. The Star Newspaper, 1.

\section{Author Notes}

The writing of this paper has been supported by University of the Western Cape Postgraduate Writing Fellowship. 